\title{
COMÉRCIO VAREJISTA DE BANANA EM CURITIBA E REGIÃO METROPOLITANA
}

\section{RETAIL MARKET OF BANANA IN CURITIBA AND METROPOLITAN REGION}

\author{
Ruy Inacio Neiva de CARVALHO' \\ Ricardo CETNARSKI FILHO² \\ Vinícius Caetano MARTIN³
}

\begin{abstract}
RESUMO
A produção de bananas (Musa spp.) no Paraná vem crescendo e Curitiba e sua Região Metropolitana representam uma importante região de consumo. Este trabalho objetivou caracterizar o mercado varejista de bananas em Curitiba e Região Metropolitana no período de Fevereiro de 1999 a Janeiro de 2000. Selecionaram-se quatro mercados varejistas representativos nos quais foram realizadas visitas mensais para coleta de informações de cultivares ofertadas, preços praticados (corrigidos pelo INPC-IBGE), embalagens utilizadas, estádio de maturação e grau de lesões na casca das frutas. As cultivares de banana comercializadas no período foram a 'Nanicão', 'Prata', 'Maçã' e 'Ouro'. As cultivares 'Prata', 'Nanicão' e 'Maçã' foram encontradas em 100\%, 98\% e 83\% das visitas, respectivamente, e a banana 'Ouro', foi encontrada apenas em $16 \%$ das visitas. A cultivar 'Nanicão' foi comercializada com o menor preço médio mensal (de $R \$ 0,41$ a $R \$ 0,81 / \mathrm{kg}$ ), seguida pela 'Prata' (de $R \$ 0,97$ a $R \$ 1,58 / \mathrm{kg}$ ) e a 'Maçã' (de $R \$ 1,54$ a $R \$ 1,88 / \mathrm{kg}$ ). $A$ banana 'Ouro', embora não presente na maioria das visitas, apresentou preço médio praticado de $\mathrm{R} \$ 1,36$ a $\mathrm{R} \$ 1,82 / \mathrm{kg}$. O estádio médio de maturação para as cultivares 'Nanicão', 'Prata' e 'Maçã' teve variação de 53 a $81 \%$ da casca com coloração amarela, enquanto para a cultivar 'Ouro' houve variação de 50 a 100\%. A comercialização foi realizada em pencas inteiras ou divididas e colocadas a granel ou penduradas em ganchos. As lesões na casca encontraram-se na faixa de lesões leves e médias.
\end{abstract}

Palavras-chave: Musa spp. banana, comércio, qualidade.

\begin{abstract}
The production of bananas (Musa spp.) in Paraná is growing and Curitiba and Metropolitan Area represent an important consumption area. This work aimed to characterize the retail market of bananas in Curitiba and Metropolitan Area in the period from February, 1999 to January, 2000. Four representative retail markets were selected and visited monthly for collection the information about cultivars presented, practiced prices (corrected to February, 1999), used packings, maturation stage and intensity of lesions in the peel of the fruits. Banana cultivars marketed in the studied period were 'Nanicão', 'Prata', 'Maçã' and 'Ouro'. The cultivars 'Prata', 'Nanicão' and 'Maçã' were commercialized in 100\%, $98 \%$ and $83 \%$ of the visits, respectively, and the cultivar 'Ouro' was found only in $16 \%$ of the visits. 'Nanicão' cultivar was marketed with the lowest average monthly price (from $R \$ 0,59$ to $R \$ 0,81 / \mathrm{kg}$ ) followed by banana 'Prata' (from $R \$ 0,98$ to $R \$ 1,58 / \mathrm{kg}$ ) and 'Maçã' (from $R \$ 1,54$ to $R \$ 1,88 / \mathrm{kg}$ ). The banana 'Ouro', although not present in the majority of visits, presented average price from $R \$ 1,36$ to $R \$ 1,82 / \mathrm{kg}$. The maturiry stage of 'Nanicão', 'Prata' and 'Maçã' showed a variation from 53 to $81 \%$ of yellow color of peel, while the cultivar 'Ouro' presented a variation from 50 to $100 \%$. The banana market was realized with entire bunchs or clusters that were putted in bulk or hung in hooks. The lesions in the peel were classified as light and middle.
\end{abstract}

Key-words: Musa spp., banana, market, quality.

\footnotetext{
${ }^{1}$ Eng. Agrônomo, CREA 24.342-D, Dr., Professor Adjunto II da PUCPR, Campus São José dos Pinhais, Rodovia BR 376, km 14. Caixa Postal 129 - CEP 83010-500. São José dos Pinhais-PR. E-Mail: ruy@rla01.pucpr.br

2 Eng. Agrônomo, Mestrando da UFPR. Curitiba-PR.

${ }^{3}$ Eng. Agrônomo, São José dos Pinhais-PR.
} 


\section{INTRODUÇÃO}

A bananeira é cultivada há milhares de anos, expandindo suas fronteiras a partir dos centros de origem e atingindo uma imensa área tropical e subtropical, onde vivem milhões de pessoas que têm no seu cultivo sua principal fonte de alimentação e/ou sobrevivência. Há regiões em que o consumo per capita chega a aproximar-se de $1 \mathrm{~kg} / \mathrm{dia}$ e em outras gera benefícios econômicos através de sua contribuição ao produto interno bruto, ao estabelecimento de fontes de emprego e na formação de divisas (1). Em inúmeras pequenas nações da América Central a banana constitui-se na principal fonte de divisas (11). No Brasil a banana tem um papel fundamental na alimentação da população, na fixação de mão-de-obra no meio rural e na geração de divisas para o país (13).

A produção mundial de frutas em 2000 foi de $459.210 .720 \mathrm{tM}$ e a banana representou $12,8 \%$ desta produção, sendo ultrapassada apenas pela laranja $(14,4 \%)$. A produção mundial de bananas cresceu de 46.925.552 tM em 1990 para 58.687.214 tM em 2000. A produção brasileira de bananas permaneceu estável ao longo da década de 1990 , variando entre 5,5 a 5,8 milhões de tM e em 2000 a produção nacional aumentou para 6.339.350 tM. Em 2000, a banana representou $16,5 \%$ da produção brasileira de frutas, sendo ultrapassada apenas pela laranja (59,3\%) (7).

A banana é cultivada em todos os estados brasileiros, desde a faixa litorânea até os planaltos do interior, embora o seu plantio sofra restrições, em virtude de fatores climáticos. Quanto a distribuição regional da produção, registram-se os seguintes índices: Sudeste (33\%), Nordeste (29\%), Norte (18\%), Sul $(11 \%)$ e Centro-Oeste $(9 \%)$. Com relação aos estados maiores produtores, tem-se a seguinte ordem: Bahia (28\%), São Paulo (14\%), Santa Catarina (9\%), Pará (9\%), Minas Gerais (8\%). A produção restante $(42 \%)$ é originária dos demais estados (3).

A região Sul do Brasil não se destaca no cultivo de bananas quando comparada a outras regiões do país, porém a sua produção tem importante participação no mercado local. O Paraná produziu 8.990 t de banana em 1998, representando $17,4 \%$ da produção do Sul do Brasil e apenas $1,7 \%$ da produção nacional (9).

A quase totalidade da banana produzida no Brasil é comercializada 'in natura' nos mercados atacadistas e feiras-livres, através das seguintes transações: a) banana verde em cachos ou pencas; b) banana madura, no atacado, em pencas ou em cachos; c) banana madura, no varejo, em dúzias ou peso. Esta comercialização passa por diversas fases de intermediação. Sabe-se que do total produzido $75,2 \%$ são entregues a intermediários, $10,0 \%$ se destina ao consumo na propriedade e $11 \%$ são vendidos diretamente ao consumidor. Pequenas porcentagens, ou seja, 2,0\% e 1,3\% são entregues à cooperativas e indústrias, respectivamente (2).

A banana é uma fruta com alto rendimento por hectare, a planta tem um ciclo curto, é de fácil propagação, tem uma produção contínua, permite o manuseio da fruta verde, pode ser armazenada por muito tempo ou amadurecida em poucos dias (10). As qualidades alimentícias e comerciais da banana são influenciadas pelas condições de amadurecimento e armazenamento, bem como pelas condições de comercialização.

A comercialização da banana tem sido objetivo de diversos estudos na década de 1990 principalmente no Sul do Brasil onde há importação da banana de outros Estados pois a produção local é baixa. As análises do mercado da banana são realizadas com dados de Centrais de Abastecimento $(4 ; 5)$ ou por meio de visitas a mercados varejistas locais representativos da região estudada $(6 ; 8 ; 12)$.

O objetivo deste trabalho é caracterizar o mercado varejista de bananas em Curitiba e Região Metropolitana no período de Fevereiro de 1999 a Janeiro de 2000.

\section{MATERIAL E MÉTODOS}

Os dados de cultivares ofertadas, preços praticados, embalagens utilizadas (forma de exposição das frutas), estádio de maturação e grau de lesões na casca das frutas, foram obtidos através de visitas mensais em quatro mercados varejistas representativos da região de Curitiba e Região Metropolitana. Foram escolhidos dois supermercados e dois hipermercados de grandes redes do Sul do Brasil. Os preços reais foram corrigidos pelo INPCIBGE para comparação entre os meses do ano, com base o mês de fevereiro de 1999.

O delineamento experimental utilizado foi o de blocos ao acaso, com quatro repetições, sendo cada mercado uma repetição, e doze tratamentos, que foram as análises mensais efetuadas.

Os dados de preços corrigidos foram analisados estatisticamente para cada cultivar, quando esta foi encontrada em $100 \%$ das visitas. As médias obtidas foram comparadas pelo teste de Tukey a $5 \%$ de probabilidade. A comparação estatística entre os preços das cultivares foi realizada por meio de análise de tratamentos com repetições diferentes, pois não havia oferta em todos os mercados ao longo do período estudado.

O estádio de maturação foi avaliado em porcentagem de coloração amarela da casca, assim as frutas foram classificadas como: verde, $25 \%$ amarela, 50\% amarela, $75 \%$ amarela e $100 \%$ amarela.

As lesões foram classificadas como:

- Graves - fruta com muitas manhas escuras na casca, 'imprópria para venda'.

- Médias - fruta com algumas manchas na casca, 'com possibilidade de venda'.

- Leves - fruta com poucas manchas na casca, 'boa para venda'.

- Sem lesões - fruta sem manchas na casca, 'ideal para a venda'. 


\section{RESULTADOS E DISCUSSÃO}

As cultivares de banana comercializadas no período estudado foram a 'Nanicão', a 'Prata', a 'Maçã' e a 'Ouro'. Somente a banana 'Prata' esteve presente em todos os mercados em todos os meses do ano. A cultivar 'Nanicão' foi ofertada em $98 \%$ das visitas, em apenas um mês não esteve presente em um mercado. A cultivar 'Maçã' foi encontrada em $83 \%$ das visitas, e somente em um mercado foi encontrada em todas as visitas. A banana 'Ouro' foi encontrada apenas em $16 \%$ das visitas, sendo que em dois mercados não foi encontrada em nenhuma visita (Tabela 1).

TABELA 1 - Oferta de diferentes cultivares de bananas em quatro mercados varejistas de Curitiba e Região Metropolitana de fevereiro de 1999 a janeiro de 2000 .

\begin{tabular}{|c|c|c|c|c|c|c|c|c|c|c|c|c|c|}
\hline \multirow[b]{2}{*}{ Mercados } & \multirow[b]{2}{*}{ Cultivares } & \multicolumn{12}{|c|}{ Meses } \\
\hline & & $\begin{array}{l}\text { Fev } \\
99\end{array}$ & $\begin{array}{l}\text { Mar } \\
99\end{array}$ & $\begin{array}{l}\text { Abr } \\
99\end{array}$ & $\begin{array}{l}\text { Mai } \\
99\end{array}$ & $\begin{array}{l}\text { Jun } \\
99\end{array}$ & $\begin{array}{l}\text { Jul } \\
99\end{array}$ & $\begin{array}{l}\text { Ago } \\
99\end{array}$ & $\begin{array}{l}\text { Set } \\
99\end{array}$ & $\begin{array}{l}\text { Out } \\
99\end{array}$ & $\begin{array}{l}\text { Nov } \\
99\end{array}$ & $\begin{array}{l}\text { Dez } \\
99\end{array}$ & $\begin{array}{l}\text { Jan } \\
00\end{array}$ \\
\hline \multirow{4}{*}{ I } & Nanicão & & & & & & & & & & & & \\
\hline & Maçã & & & & & & & & & & & & \\
\hline & Prata & & & & & & & & & & & & \\
\hline & Ouro & & & & & & & & & & & & \\
\hline \multirow{4}{*}{ II } & Nanicão & & & & & & & & & & & & \\
\hline & Maçã & & & & & & & & & & & & \\
\hline & Prata & & & & & & & & & & & & \\
\hline & Ouro & & & & & & & & & & & & \\
\hline \multirow{4}{*}{ III } & Nanicão & & & & & & & & & & & & \\
\hline & Maçã & & & & & & & & & & & & \\
\hline & Prata & & & & & & & & & & & & \\
\hline & Ouro & & & & & & & & & & & & \\
\hline \multirow{4}{*}{ IV } & Nanicão & & & & & & & & & & & & \\
\hline & Maçã & & & & & & & & & & & & \\
\hline & Prata & & & & & & & & & & & & \\
\hline & Ouro & & & & & & & & & & & & \\
\hline \multicolumn{2}{|l|}{ Presença $n$} & 75 & 75 & 81 & 81 & 87 & 75 & 68 & 75 & 81 & 62 & 68 & 68 \\
\hline
\end{tabular}

Legenda:

\section{AUSENTE}

A cultivar 'Prata' teve seu maior preço durante o mês de agosto e em fevereiro e março foi comercializada com o menor preço (Tabela 2). Os menores preços normalmente estão relacionados com a maior oferta da fruta, comum nos meses mais quentes de verão, enquanto nos meses mais frios a oferta decresce e, consequentemente, há uma tendência de os preços se elevarem. Os menores preços encontrados nos meses de verão também podem estar associados à maior oferta de frutas de clima temperado cultivadas na região, principalmente a maçã, gerando uma competição que provoca redução de preços. O preço da banana 'Prata' na CEASA/PR, responsável por $57 \%$ do volume comercializado de bananas no Sul do Brasil, no período de 1981 a 1990 não apresentou variação nos meses do ano, talvez pela característica do mercado atacadista abastecido pela produção de bananas de outros estados tradicionalmente produtores como São Paulo e Santa Catarina $(4 ; 5)$. Apesar de não haver variação mensal de preços no mercado atacadista num período de 10 anos, a variação no mercado varejista pode ser mais facilmente encontrada pela própria competição entre os mercados que procuram oferecer a fruta com preços diferenciados para atrair os consumidores.

\section{PRESENTE}

Os preços praticados foram diferentes para as cultivares encontradas nos mercados. A banana 'Maçã' foi encontrada sempre com preços mais elevados que a banana 'Nanicão' e nos meses de abril e junho apresentou também preços mais elevados que a banana 'Prata'. A banana 'Prata' apresentou preços mais elevados que a banana 'Nanicão' de maio a outubro e em dezembro e janeiro. Somente em quatro meses do ano as bananas 'Prata' e 'Nanicão' foram comercializadas com preços semelhantes (TABELA 3). A banana 'Ouro' foi comercializada com preços médios elevados variando de $R \$ 1,36 / \mathrm{kg}$ (fevereiro) a $\mathrm{R} \$ 1,82 / \mathrm{kg}$ (setembro). No período de março a julho os preços oscilaram entre $R \$ 1,60$ e $R \$ 1,70 / \mathrm{kg}$ e em outubro foi de $R \$ 1,79 / \mathrm{kg}$. Nos outros meses esta cultivar não foi ofertada.

O estádio de maturação médio anual da banana comercializada variou pouco entre as cultivares (de 66,7 a $73,7 \%$ da casca com coloração amarela). Para as cultivares 'Nanicão', 'Prata' e 'Maçã', a amplitude média dos valores de maturação variaram de 53 a $81 \%$ da casca amarela. Para a Cultivar 'Ouro', a amplitude dos valores de maturação foi de 50 a $100 \%$ da casca amarela, mostrando que as condições de oferta desta cultivar é muito variada (Figura 1). 
CARVALHO, R.I.N. et al. Comércio varejista de banana em...

TABELA 2 - Preço médio mensal da banana 'Prata' comercializada no mercado varejista de Curitiba e Região Metropolitana no período de fevereiro de 1999 a janeiro de 2000.

\begin{tabular}{|c|c|}
\hline Mesesiano & Preço médio* (Rq, $\left.{ }^{\prime} \mathrm{kq}\right)$ \\
\hline Fevereiro'g9 & $0.97 \quad d^{\text {th }}$ \\
\hline Marcoigg & 0.98 \\
\hline Abriligg & 1.11 \\
\hline Maio'99 & 1.23 abcd \\
\hline Junho/g9 & $1.18 \mathrm{bcd}$ \\
\hline Julho/99 & 1.27 abcd \\
\hline Agostog9 & $1.58 \mathrm{a}$ \\
\hline Setembro'99 & $1.38 \mathrm{abc}$ \\
\hline Outubro/99 & 1.32 abcd \\
\hline Novembro'g9 & 1.24 abcd \\
\hline Dezembro'g9 & $1.49 a b$ \\
\hline Janeiro'00 & $1.36 \mathrm{abc}$ \\
\hline
\end{tabular}

*Preços corrigidos com base em fevereiro/1999 pelo índice INPC-IBGE.

${ }^{* *}$ Médias seguidas de mesma letra não diferem entre si pelo teste de Tukey ao nível de $5 \%$ de probabilidade.

TABELA 3 - Preços praticados para as cultivares de banana 'Maçã', 'Prata' e 'Nanicão' em mercados varejistas de Curitiba e Região Metropolitana de fevereiro de 1999 a janeiro de 2000

\begin{tabular}{|c|c|c|c|}
\hline \multirow[t]{2}{*}{ Mesesiano } & \multicolumn{3}{|c|}{ Precos $^{*}\left(\mathrm{Rq}_{j} \mathrm{~kg}^{\prime}\right)$} \\
\hline & 'maçẫ' & 'Prata' & 'Nanicẫo' \\
\hline Fevereiro'99 & $1.69 a^{*}$ & $0.97 \mathrm{ab}$ & $0.64 \mathrm{~b}$ \\
\hline Marçoigg & $1.69 \mathrm{a}$ & $0.98 \mathrm{ab}$ & $0.63 \mathrm{~b}$ \\
\hline Abriligg & $1.72 \mathrm{a}$ & $1.11 \mathrm{~b}$ & $0.65 \mathrm{~b}$ \\
\hline Maio' 99 & $1.56 \mathrm{a}$ & $1.23 \mathrm{a}$ & $0.53 \mathrm{~b}$ \\
\hline Junho/99 & $1.72 \mathrm{a}$ & $1.18 b$ & $0.66 \mathrm{c}$ \\
\hline Julho'99 & $1.62 \mathrm{a}$ & $1.27 \mathrm{a}$ & $0.48 \mathrm{~b}$ \\
\hline Agosta'99 & $1.78 \mathrm{a}$ & $1.58 \mathrm{a}$ & $0.74 \mathrm{~b}$ \\
\hline Setembroig9 & $1.79 \mathrm{a}$ & $1.38 \mathrm{a}$ & $0.80 \mathrm{~b}$ \\
\hline Outubro'99 & $1.66 \mathrm{a}$ & $1.32 \mathrm{a}$ & $0.81 \mathrm{~b}$ \\
\hline Nowembroig9 & $1,73 a$ & $1.24 \mathrm{ab}$ & $0.76 \mathrm{~b}$ \\
\hline Dezembroig9 & $1.88 \mathrm{a}$ & $1.49 \mathrm{a}$ & $0.71 \mathrm{~b}$ \\
\hline Janeiro'00 & $1.54 \mathrm{a}$ & $1.36 \mathrm{a}$ & $0.41 \mathrm{~b}$ \\
\hline
\end{tabular}

*Preços corrigidos com base em fevereiro/1999 pelo índice INPC-IBGE

${ }^{* *}$ Médias seguidas de mesma letra na linha não diferem entre si pelo teste de Tukey ao nível de $5 \%$ de probabilidade.

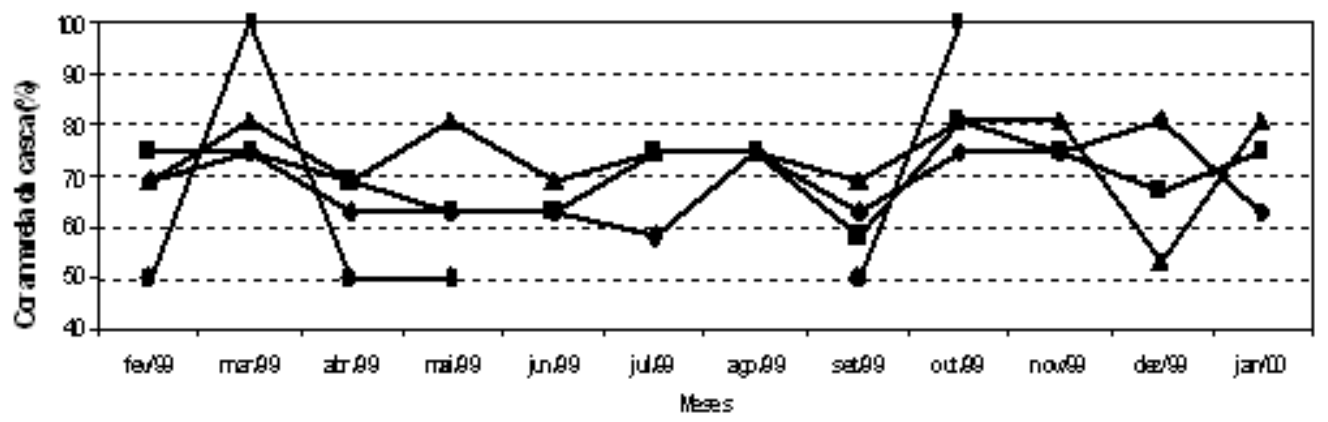

\begin{tabular}{|c|c|}
\hline 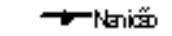 & T-0ro \\
\hline
\end{tabular}

FIGURA 1 - Coloração da casca das bananas comercializadas no mercado varejista de Curitiba e Região Metropolitana de fevereiro de 1999 a janeiro de 2000. 
As cultivares 'Nanicão', 'Prata' e 'Maçã' são mais tradicionais e, consequentemente, mais procuradas para o consumo diário. Esta fato gera uma maior circulação das frutas nas prateleiras, havendo constante reposição das mesmas e evitando o amadurecimento completo por falta de procura pelo consumidor. Estas cultivares de cultivo tradicional por produtores tecnificados recebem a climatização para homogeneização da maturação antes de serem comercializadas no mercado varejista. Sendo a banana uma fruta climatérica, a homogeneização da maturação é fator fundamental para viabilização do comércio de frutas de qualidade homogênea. Já a banana ouro é menos tradicional, tanto para o cultivo quanto para a procura pelos consumidores, gerando inconstância de oferta e demanda nos mercados e, consequentemente, o tempo da fruta na prateleira é maior, proporcionando avanço da maturação. Esta característica dificulta ainda mais a comercialização uma vez que a variedade madura sofre queda de frutos da penca, deixando de ser preferida pelo consumidor.

A comercialização da banana foi realizada em pencas inteiras ou divididas e colocadas a granel ou penduradas em ganchos. Este tipo de exposição mostra a preocupação de não causar danos as frutas, e assim minimizar as perdas. As lesões na casca encontraram-se na faixa de lesões leves e médias, caracterizando uma forma de manejo (colheita, classificação, armazenamento e transporte) e exposição do produto ainda não totalmente adequada. As bananas são colhidas verdes e, nesta fase, os danos leves não aparecem tornando-se visíveis apenas com o avanço da maturação da fruta que acontece muitas vezes no mercado atacadista, fornecedor do mercado varejista. Muitas frutas chegam ao mercado já com injúrias e, desta forma, o comerciante pouco pode fazer para melhorar a qualidade da banana, podendo apenas retardar o desenvolvimento das lesões pelo cuidado na exposição ao consumidor.

\section{CONCLUSÕES}

As bananas 'Prata', 'Nanicão', 'Maçã' estão disponíveis durante todo o ano e a banana 'Ouro' é encontrada esporadicamente em alguns meses do ano no mercado varejista de Curitiba e Região Metropolitana.

A cultivar 'Nanicão' é ofertada por menores preços enquanto que a 'Maçã' é comercializada com preços mais elevados entre as bananas disponíveis no mercado varejista de Curitiba e Região Metropolitana.

As cultivares de banana são ofertadas com a maior parte da casca com coloração amarela.

A comercialização é realizada em pencas inteiras ou divididas e colocadas a granel ou penduradas em ganchos.

As lesões na casca das bananas encontramse na faixa de lesões leves e médias, ainda possibilitando a venda da fruta, o que indica um manejo pós-colheita satisfatório.

\section{REFERÊNCIAS BIBLIOGRÁFICAS}

1. ALVES, E.J. A atividade banana nos países produtores. Brasília: Embrapa-CNPMF, 1990. 31p.

2. ALVES, E.J. A cultura da banana no Brasil e proposições para o seu melhoramento. Brasília: Embrapa-CNPMF, 1991. 40p.

3. ALVES, E.J.; DANTAS, J.L.L.; SOARES FILHO, W.S.; SILVA, S.O.; OLIVEIRA, M.A.; SOUZA, L.S.; CINTRA, F.L.D.; BORGES, A.L.; OLIVEIRA, ${ }^{\mathrm{M}} \mathrm{M} . \mathrm{G}$.; OLIVEIRA, S.L.; FANCELLI ,M.; CORDEIRO, Z.J.M.; SOUZA, J.S. Banana para exportação: aspectos técnicos da produção. Brasília: Embrapa-SPI, 1997. 106p. (Série Publicações Técnicas FRUPEX; 18).

4. CARVALHO, R.I.N. Procedência, volume e preço da banana comercializada na CEASA/PR, no período de 1981-1990. Revista do Setor de Ciências Agrárias, Curitiba, v.11, n.1-2, p.93-100, 1991.

5. CARVALHO, R.I.N.; FIORAVANÇO, J.C.; PAIVA, M.C.; MANICA, I. Quantidade e preço da banana comercializada nas CEASAS do Paraná, Santa Catarina e Rio Grande do Sul. Agropecuária Catarinense, Florianópolis, v.7, n.2, p.31-32, 1994.

6. FAGUNDES, G.R.; YAMANISHI, O.K.; BORGO, L.A.; MANICA, I. Atributos de qualidade da banana 'Prata' comercializada entre setembro/97 e agosto/98, em 4 estabelecimentos de Brasília-DF. Revista Brasileira de Fruticultura, Jaboticabal, v.21, n.3, p.372-374, dezembro, 1999.

7. FAO. Agricultures production. Disponível: www.fao.org/Statistical databases/Agriculture/Agriculture production. Capturado em 04/04/2001.

8. FIORAVANÇO, J.C.; PAIVA, M.C.; CARVALHO, R.I.N., MANICA, I. Qualidade da banana "branca" comercializada em Porto Alegre, de outubro de 1991 a junho de 1992. Científica, São Paulo, v.23, n.1, p.165-170, 1995.

9. IBGE. Anuário Estatístico do Brasil/Instituto Brasileiro de Geografia e Estatística. Volume 58. 1998. p.26.

10. MANICA, I. Banana. Porto Alegre: Cinco Continentes, 1997. 485p.

11. PADOVANI, M.I. Banana um mercado crescente para este alimento milenar. São Paulo: Ícone, 1986. 104p.

12. PAIVA, M.C.; CARVALHO, R.I.N.; FIORAVANÇO, J.C.; MANICA, I. Características da banana "nanicão" comercializada em Porto Alegre de outubro/91 a junho/92. Ciência e Agrotecnologia, Lavras, v.20, n.3, p.275-278, jul./set., 1996.

13. SOUZA, J.S.; TORRES FILHO, P. Aspectos sócioeconômicos. In: ALVES, E.J. (Org.) A cultura da Banana: aspectos técnicos, sócioeconômicos e agroindustriais. Brasília: Embrapa-SPI/Embrapa-CNPMF, 1997. p.507-524.

Recebido em 11/05/2001

Aceito em 21/07/2003

Scientia Agraria, v.5, n.1-2, p.9-13, 2004. 